\title{
Prevalence and resistance of bacterial strains isolated from chicken beddings in rural households
}

\author{
Dermatas $^{1}$, C. Voidarou ${ }^{2}$, K. Akrida - Demertzi ${ }^{1}$ and P. G. Demertzis ${ }^{1}$ \\ ${ }^{1}$ University of Ioannina, Section of Industrial and Food Chemistry, Department of Chemistry, \\ Panepistimioupolis, Ioannina, Greece \\ ${ }^{2}$ Department of Public Health, Regional Unit of Arta - Prefecture of Epirous, Greece
}

\begin{abstract}
The main interest of researchers is focused on the microbiology of the industrial poultry beddings. In this study the microbiology and the microbial resistance of strains isolated from composite samples of poultry (gallus gallus domesticus) beddings originating from rural households has been investigated. In the area of Arta (Epirus, Greece) samples were collected from 300 rural households. These samples were classified regarding the following 4 criteria: (a) the size of the chicken flock, $(b)$ the presence of different poultry species in the same household, (c) the presence of small ruminants in the same household and (d) differences in feeding practices. Results reveal that the microbiology of the beddings was mostly affected by the presence of small ruminants in the same household and the administration of concentrated feeds. Microbial resistance followed the same distribution pattern. The most resistant strains were isolated from samples originating from households breeding both poultry and small ruminants. Feeding with concentrated feeds was a determinant factor and probably the link between resistance and prevalence.
\end{abstract}

Keywords: chicken, Salmonella, Listeria, microbial, resistance

\section{Introduction}

Rural households breed chickens and hens throughout the world [1-3]. The term «village or family poultry» refers to small flocks raised by individual farm families and these animals represent a valuable source of animal protein for the members of the households through meet and eggs, but also in many cases an additional source of income [4-5]. Their husbandry is simple since they are bred in the backyard of these households and are fed mostly by whatever they graze and additionally by concentrated feeds. In terms of finance and human resources it is the cheapest form of farming and historically the most ancient [6]. Usually this kind of rural production evades the official statistics due to the practical impossibility to gather reliable data. Yet, the size of it is not negligible but rather comparable to the industrial one, particularly in the developing countries where local economies are based on barter trade. Even in the developed countries a strong tradition exists favoring such practices. Urban legends claim that the organoleptic characteristics of the chicken and eggs originating from a rural household are superb in comparison with the industrial ones. In many cases these birds coexist in the same environment with other domestic species of poultry such as turkeys and other species of mammals such as small ruminants. The bedding of these birds consists mainly of straw and occasionally small tree branches and leafs are added. In various time intervals this bedding is collected and disposed to a ditch and after a while it is used as a fertilizer.

Research had mostly focused on the beddings of the commercial poultry industry. Indeed the amounts of litter of industrial origin are huge and their disposal and treatment give rise to serious challenges concerning the environment as well as the Public Health. Yet, it is relatively easy to the national authorities to pinpoint the industrial farms and impose regulations. The amounts of beddings of household origin in a national level are not negligible. Definitely the amount produced per household is much smaller but the number of rural households is immense compared to industrial poultry units. Furthermore, in the cases of rural households there are not any practical effective controls for the disposal and treatment of the bedding, a fact implying that these materials are disseminated to the environment in uncontrollable ways. Important environmental concerns such as the nitrate and phosphate runoffs to streams, rivers and lakes as well as the escape of gasses (ammonia) which result in unpleasant odors have been reported [7]. The microbiology of industrial beddings as well as their biological or otherwise treatment has also been studied. The case of industrial breeding is rather «simple» in the sense that all the parameters (feedstuff, age of the birds, number of birds per area unit, type of bedding etc.) are known and under control. On the other hand rural household breeding is a very complicate case due to the variations of husbandry and nutrition practices from household to household and from area to area. There are not any generally accepted practices and this variability may cause due to chaotic interactions serious environmental or Public Health issues. Dumping such material in a ditch without any kind of treatment and using it as fertilizer may load the environment with dangerous pathogenic bacteria or with resistance genes. The dissemination of resistance genes to the environment by flies, rodents and birds has been documented in many reports. 
This study is an attempt to investigate the microbiology of these beddings and the relative resistance of isolated bacterial species with special Public Health interest.

\section{Materials And Methods}

\subsection{Samples}

Composite samples of beddings (stools and litter) were collected from 300 randomly selected rural household from the area of Arta (Epirus, Greece).

\subsection{Classification}

The samples were classified with respect to the following 4 criteria:

-A) the size of the flock: up to m10 birds (Gallus domesticus), 10-30 birds and more than 30 birds

-B) the presence or not of other poultry species like turkeys, ducks etc.

-C) the presence or not of small ruminants (sheep and goats)

-D) the administration of households' leftovers of plant origin (potatoes, tomatoes etc) or the administration of industrial grade concentrated feeds (corn, barley etc).

From these 4 criteria, 15 study groups emerged (Table 1).

\subsection{Bacterial isolation and identification}

Salmonella spp, Listeria spp, Clostridium perfringens (vegetative forms) and Clostridium perfringens (spores) were isolated and identified as described in Bergey's manual.

\subsection{Microbial susceptibility}

Salmonella spp and Listeria spp strains were tested with the disc diffusion method for resistance against the following20 antimicrobial agents [8]: penicillin G, amoxicillin, ampicillin, cefotaxime, cefalotine, cloramphenicol, ciprofloxacin, clindamycin, enrofloxacin, erythromycin, gentamicin, kanamycin, nalidixic acid, neomycin, oxytetracycline, streptomycin, sulfamethoxasole/trimethoprim, terramycine, vancomycin, oxolinic acid.

\subsection{Prevalence of bacteria}

\section{Results}

Table 1 shows the 15 study groups and the prevalence of Salmonella spp, Listeria spp, Clostridium perfringens (vegetative forms) and Clostridium perfringens (spores) isolated from the samples of these groups. Salmonella spp strains were isolated from 24 samples (8.00\%) belonging to 8 groups. Seventeen (17) of the 24 strains $(70.83 \%)$ are isolated from the groups No 5, No 10 and No 15, which differ only in the size of the flock. However, this is not a statistically significant finding which implies that the size of the flock is not a critical factor. By comparison of groups No 1, No2, No3 and No4 (same size and not fed with concentrated feeds) positive samples are found only in groups No3 and No4, which are characterized by the presence of small ruminants in the household in contrast with groups No1 and No2. Similar is the picture in groups No 8 and No9 with respect to groups No6 and No7, as well as in group No 13 with respect to group No 11 . These findings suggest that the presence of small ruminants in the household is a critical factor concerning the incidence of Salmonella spp. Group No 4 and Group No 5 differ only in the feeding practice (in the latter the birds are fed with concentrated feeds). In group No5 Salmonella spp strains' incidence is more than 3 times greater than the incidence in group No 4. Greater incidences are also observed in Groups No 10 and No15 with respect to groups No9 and No14. These findings suggest that concentrated feeds are also a favorable factor for Salmonella spp. Finally groups that originate from households without the presence of small ruminants and where the birds are fed with leftovers, there weren't any samples positive to Salmonella spp. This observation supports the previous conclusions.

Listeria spp strains were isolated from 11 samples (3.66\%) belonging to 7 groups. Comparison of the incidences between various groups in the exact manner as in the case of Salmonella spp leads to similar conclusions. The incidence of Listeria spp is neither affected by the size of the flock nor by the presence of other poultry species, while it is affected by the presence of small ruminants and by the feeding with concentrated feeds. However, the tendency of the last factor is not as strong as in the case of Salmonella spp

C. perfringens vegetative forms were isolated from 29 samples $(9.67 \%)$ belonging to 7 groups. By comparing the different groups it is concluded that -in contrast with the two previous bacteria- the size of the flock is an important factor concerning the incidence of the vegetative forms of $C$. perfringens. Still, the presence of small ruminants in the household remains an important factor. The data is not clearly distributed among the various groups to conclude whether or not the presence of other poultry species and the feeding of concentrated feeds affect the incidence of this bacterium. However, considering the fact that 19 out of the total 29 samples belong to groups No 10 and No 15 seems that these two factors contribute to the incidence of vegetative $\mathrm{Cl}$. perfringens. 
C. perfringens spores were isolated from 38 samples (12.66\%) belonging to 8 groups. Size of the flock is not a critical factor. The presence of small ruminants in the households affects the incidence of $C$. perfringens more than the presence of other poultry species. Concentrated feeds certainly affect this incidence.

\subsection{Microbial resistance}

Table 2 shows the antimicrobial resistance of the isolated Salmonella spp and Listeria spp strains to the antimicrobials agents. The importance of these species is obvious both to public health and to veterinary medicine. Salmonella spp strains showed absolute susceptibility against 6 antibiotic substances while Listeria spp against 15. Absolute resistance was observed against 5 antibiotics in the case of Salmonella spp, while against only 2 in the case of Listeria spp.

All isolated Salmonella strains were found multiresistant against at least 6 antimicrobial agents (Table 3). Furthermore, resistance and consequently susceptibility seem to follow the pattern of the incidence of this species. As the prevalence increases, so does the number of antibiotics against which resistance is observed.

Likewise in the case of Listeria spp, all isolated strains were found multiresistant. The distribution of the observed resistance does not follow clearly a pattern as in the case of Salmonella spp. However 5 out of the 7 most multiresistant strains were isolated from groups with higher prevalence.

\subsection{Prevalence of bacteria}

\section{Discussion}

It is obvious that rural households do not apply the scientific principles of animal husbandry and environmental management. This fact leads to empirical management practices which -by definition- do not take into consideration various hazards. Consequently chickens can also be directly infected by water, feeds, rodents, flies and dust [9]. Poultry beddings are considered by some authors [10] as a hostile environment for the persistence of pathogens because it is dry, it has high ammonia content and it readily heats up. Research evidence suggests that bacterial counts decrease sufficiently when beddings are composted [11]. The distribution of bacteria is not homogenous in the bedding. The top layers contain larger numbers of bacteria compared to the middle and lower layers [12]. A direct relationship was found between depth of litter and total bacteria count [11].

In the present study Salmonella spp strains' prevalence was correlated with the presence of small ruminants and the administration of concentrated feedstuffs. Researchers like Pao et al. (2005) [13] suggest that small ruminants are potential carriers of Salmonella spp and they can disseminate this species to the surrounding environment. Feedstuff could also be infected by rodents and flies. Consequently, Salmonella spp isolated from the beddings could originate either from the surrounding environment or from the digestive track of the chickens. Listeria spp is a widely spread species in the environment. According to Nightingale et al (2004) [14] healthy ruminants can be carriers of Listeria spp. The soil, the water, the grass .wild birds and the feedstuffs are also possible ways of infection. As in the case of Salmonella spp, the isolation of Listeria spp from the beddings could be attributed to the environment or to the fecal excrements of the birds. It is important to notice that household owners did not mention disease or deaths in their flocks. This suggests that either the presence of these species was in very low levels (at least lower than the infectious dose) or that the birds were adapted to the specific serotypes.

C. perfringens vegetative forms' prevalence was correlated with the size of the flock. In larger flocks more fecal excrements are produced and hence the bedding is thicker, creating anaerobic environment ideal for C. perfringens vegetative forms. This species is also disseminated in the environment by small ruminants' feces. On the other hand $C$. perfringens spores are abound in nature and it is rather surprising the fact that they were not isolated in greater rates.

\subsection{Microbial resistance}

Resistance to antibiotics of Salmonella spp and Listeria spp follows a specific pattern in this study. Although all strains of both species were found multiresistant [15-17], this resistance is more severe (number of antibiotics against which resistance is expressed) in the groups where the bacteria were isolated in greater prevalence. The link between prevalence and resistance was found to be the presence of small ruminants and the feeding of concentrated feeds. Feeding in rural households is not balanced. Even if the owners use concentrated feeds instead of leftovers, they feed their flocks empirically and in most cases the birds are overfed. This overfeeding along with the imbalance of the total intake leads to excess of nutrients in the digestive track and consequently enriches the bedding. To the same result leads the spilling of the feds over the beddings. This abundance of nutrients favors bacterial growth and covers the metabolic cost of resistance mechanisms. Another aspect of our findings is the resistance to antibiotics not used in veterinary medicine of food animals in Greece such as vancomycin, oxolinic acid, cefotaxime and others. Possibly this finding can be attributed to cross resistance with other antibiotics with similar chemical structure or with similar mode of action [18-19]. The 
area where the study was conducted is not densely populated and with few anthropogenic activities. Still, contamination from human sources cannot be dismissed. In any case it is a puzzling finding because rural household owners ere usually reluctant to use medicines on their animals which means that selective pressure in these households is not intense.

What is more alarming is the fact that the beddings are used as fertilizers, usually after remaining in a ditch for a while. Poultry beddings have been reported to contain a percentage of crude protein around $30 \%$ as well as high levels of minerals [7]. It is possible that during this process the resistance genes are disseminated to other bacteria not necessarily pathogenic (spoilage) and from these bacteria a further dissemination may occur to the environment and particularly to the vegetable garden of the household. From this garden originate the leftovers fed to the birds and to the small ruminants of the household, not to mention the owners. This circulation may function as an amplifier both to prevalence of certain bacteria and to resistance to antibiotics. Further research is needed to clarify more aspects of this situation as well as its ramifications to public health.

\section{References}

[1]. J. Adongo, Comparative advantage of a thermotolerant I-2 vaccine in the control of Newcastle disease in village chickens in Ghana. Rural Poultry E-Newsletter, Third Edition GRM International PTY LTD, 2004.

[2]. J. C. Moreki, Village poultry production in Serowe-Palapye subdistrict of Botswana. Livestock Research for Rural Development, 2010, 22:(3).

[3]. P. Spradbrow, Special requirements for village chickens,. In, Mowat N. and Rweyemu M. (eds) Vaccine Manual: The production and quality and control of veterinary vaccines for use in developing countries. Food and Agriculture Organisation of the United Nations, 1997, p.123-126.

[4]. E. B. Sonaiya, International Network for Family Poultry Development: Origins, activities, objectives and visions. Proceedings workshop on poultry as a tool in poverty eradication and promotion of gender equality held March 22 to 26, 1999. Tune Landboskole, Denmark.

[5]. C.V. McAinsh, J. Kusina, J. Madsen and O.Nyoni, Traditional chicken production in Zimbabwe. World's Poultry Science Journal,2004, 60: 233-246

[6]. American Poultry Association, The American Standards of Perfection. American Poultry Association, Inc.1983, Troy, New York.

[7]. J. Lu, S. Shanchez, C. Hofacre, J. J. Maurer, B. G. Harmon and M. D. Lee, Evaluation of broiler litter with reference to the microbial composition as assessed by using 16s rRNA and functional gene markers. Appl. Environ. Microb.,2003, 69(2):901908.

[8]. National Committee for Clinical Laboratory Standards, Performance standards for antimicrobial susceptibility testing, 14th information supplement. Document M100-S14. National Committee for Clinical Laboratory Standards (Wayne, Pa. safety control in the poultry industry. G.C. Mead), Woodhead Publishing Limited and CRC Press LLC, 2004, Cambridge, U.K., pp. 310-327.

[9]. D. B. Tinker $\mathrm{kal}$ Burton, C.H, Catching, transporting and lairage of live poultry. In: Food safety control in the poultry industry (G.C. Mead), Woodhead Publishing Limited and CRC Press LLC, Cambridge, U.K., pp. 153-173.

[10]. K. G. Wilkinson, E. Tee, R. B. Tomkins, G. Hepworth, R. Premier, Effect of heating and aging of poultry litter on the persistence of enteric bacteria. Poult. Sci., 2011, 90:10-18.

[11]. Zachary Thomas Williams, Effects of Management on the Bacterial Community Present in Poultry Litter,Faculty of Auburn University, Degree of Doctor of Philosophy, 2012.

[12]. K. J. Barker, J.L. Purswell, J. D. Davis, H. M. Parker, M. T. Kidd, C. D. McDaniel and A. S. Kiess, Distribution of bacteria at different poultry litter depths, Int. J. Poult. Sci., 2010, 9:10 - 13.

[13]. S. Pao, M. F. Khalid, A. Kalantari, Microbial profile of online- procured sprouting seeds and potential hazards associated with enterotoxigenic Bacillus spp. in homegrown sprouts. J. Food Prot., 2005, 68:1648-53

[14]. K. K. Nightingale, Y. H. Schukken, C. R. Nightingale, E. D. Fortes, A. J. Ho, J. Her, Y. T. Grohn, P. L. McDonough, Ecology and transmission of Listeria monocytogenes infecting ruminants and in the farm environment. Appl. Environ. Microbiol., 2004, 70:4458-4467

[15]. R. Antunes, C. Reu, J. C. Sousa, L. Peixe,N. Pestana, Incidence of Salmonella from poultry products and their susceptibility to antimicrobial agents. International Journal of Food Microbiology, 2003, 82:97-103.

[16]. J. J. Carraminana, C. Rota, I. Agustín, A. Herrera, High prevalence of multiple resistance to antibiotics in Salmonella serovars isolated from a poultry slaughterhouse in Spain. Veterinary Microbiology, 2004, 104: 133-139.

[17]. J. M. Miranda, A. C. Mondragon, B. Martinez, M. Guarddon, J. A. Rodriguez, Prevalence and Antimicrobial Patterns of Salmonella from Different Raw Foods in Mexico, Journal of Food Protection, 2009, 72(5): 966-971.

[18]. R. J. Astorga Márquez, A. Echeita Salaberria., A. Maldonado García, S. Valdezate Jimenez, A. Carbonero Martinez, A. Aladueña García, A. Arenas Casas, Surveillance and antimicrobial resistance of Salmonella strains isolated from slaughtered pigs in Spain. Journal of Food Protection, 2007, 70(6):1502-1506.

[19]. R. Bywater, H. Deluyker, E. Deroover, A. de Jong, H. Marion, M. McConville, T. D. Rowan, Shuster, V. Thomas, M. Valle, J. Walters, A European survey of antimicrobial susceptibility among zoonotic and commensal bacteria isolated from food-producing animals. Journal of Antimicrobial Chemotherapy, 2004, 54:744-754. 
Table 1: Incidence of bacteria isolated from poultry beddings

\begin{tabular}{|c|c|c|c|c|}
\hline $\begin{array}{l}\text { Species } \\
\text { Group }\end{array}$ & Salmonella $\mathrm{spp}$ & Listeria $\mathrm{spp}$ & $\begin{array}{l}\text { C. perfringens } \\
\text { (bacterial form) }\end{array}$ & $\begin{array}{l}\text { C. perfringens } \\
\text { (spores) }\end{array}$ \\
\hline 1) $\mathrm{A} 1, \mathrm{~B}(\mathrm{no}), \mathrm{C}(\mathrm{no}), \mathrm{D}(\mathrm{a})$ & - & - & 1 & 2 \\
\hline 2) $\mathrm{A} 1, \mathrm{~B}(\mathrm{yes}), \mathrm{C}(\mathrm{no}), \mathrm{D}(\mathrm{a})$ & - & - & - & 1 \\
\hline 3) A1, B(no), C(yes), D(a) & 1 & 1 & 2 & 2 \\
\hline 4) A1, B(yes), C(yes), D(a) & 2 & 1 & - & - \\
\hline 5) A1, B(yes), C(yes), D(b) & 7 & 2 & - & 12 \\
\hline 6) $\mathrm{A} 2, \mathrm{~B}(\mathrm{no}), \mathrm{C}(\mathrm{no}), \mathrm{D}(\mathrm{a})$ & - & - & - & - \\
\hline 7) $\mathrm{A} 2, \mathrm{~B}(\mathrm{yes}), \mathrm{C}(\mathrm{no}), \mathrm{D}(\mathrm{a})$ & - & - & - & 1 \\
\hline 8) A2, B(no), C(yes), D(a) & 1 & 2 & 3 & 5 \\
\hline 9) A2, B(yes), C(yes), D(a) & 2 & 1 & - & - \\
\hline 10) $\mathrm{A} 2, \mathrm{~B}(\mathrm{yes}), \mathrm{C}(\mathrm{yes}), \mathrm{D}(\mathrm{b})$ & 4 & 1 & 7 & 4 \\
\hline 11) $\mathrm{A} 3, \mathrm{~B}(\mathrm{no}), \mathrm{C}(\mathrm{no}), \mathrm{D}(\mathrm{a})$ & - & - & 1 & - \\
\hline 12) $\mathrm{A} 3, \mathrm{~B}(\mathrm{yes}), \mathrm{C}(\mathrm{no}), \mathrm{D}(\mathrm{a})$ & - & - & - & - \\
\hline 13) A3, B(no), C(yes),D(a) & 1 & - & 3 & - \\
\hline 14) A3, B(yes), C(yes),D(a) & - & - & - & - \\
\hline 15) A3, B(yes), C(yes),D(b) & 6 & 3 & 12 & 11 \\
\hline Total & 24 & 11 & 29 & 38 \\
\hline
\end{tabular}

A: size of the flock (1) up to 10 birds, (2) 10-20 birds (3) more than 20 birds

B: presence of other poultry species in the household

$\mathrm{C}$ : presence of small ruminants in the household

D: feeding practice (a) leftovers of vegetable origin, (b) concentrated feeds

Table 2: Resistance of Salmonella spp of Listeria spp strains isolated from poultry beddings, against 20 antimicrobial agents.

\begin{tabular}{|c|c|c|c|c|c|c|}
\hline & \multicolumn{3}{|c|}{ Salmonella $\operatorname{spp}(\mathrm{n}=24)$} & \multicolumn{3}{|c|}{ Listeria $\operatorname{spp}(\mathrm{n}=11)$} \\
\hline Resistance & $\mathrm{S}$ & $\mathrm{I}$ & $\mathrm{R}$ & $\mathrm{S}$ & $\mathrm{I}$ & $\mathrm{R}$ \\
\hline \multicolumn{7}{|l|}{ Antibiotic } \\
\hline Penicillin & - & - & 24 & 11 & - & - \\
\hline Amoxicillin & 8 & - & 16 & 11 & - & - \\
\hline Ampicillin & 8 & - & 16 & 11 & - & - \\
\hline Cefotaxime & 24 & - & - & 11 & - & - \\
\hline Cefalotine & 24 & - & - & 11 & - & - \\
\hline Cloramphenicol & - & - & 24 & 11 & - & - \\
\hline Ciprofloxacin & 24 & - & - & 11 & - & - \\
\hline Clindamycin & - & - & 24 & - & 2 & 9 \\
\hline Enrofloxacin & 24 & - & - & 11 & - & - \\
\hline Erythromycin & - & - & 24 & 11 & - & - \\
\hline Gentamycin & 24 & - & - & 11 & - & - \\
\hline Kanamycin & 5 & - & 19 & 11 & - & - \\
\hline Nalixidic acid & 9 & - & 15 & - & - & 11 \\
\hline Neomycin & 8 & - & 16 & 11 & - & - \\
\hline Oxytetracycline & 3 & - & 21 & 2 & 1 & 8 \\
\hline Streptomycin & 3 & - & 21 & 11 & - & - \\
\hline $\begin{array}{l}\text { Sulfamethoxasole/ } \\
\text { trimethoprim }\end{array}$ & 24 & - & - & 11 & - & - \\
\hline Terramycin & 2 & - & 22 & 2 & 3 & 6 \\
\hline Vancomycin & - & - & 24 & 11 & - & - \\
\hline Oxolinic acid & 3 & - & 15 & - & - & 11 \\
\hline
\end{tabular}

Table 3: Resistance to antibiotics of Salmonella spp and Listeria spp isolated strains from poultry beddings, with respect to their incidence.

\begin{tabular}{|l|l|l|}
\hline Species & Salmonella spp & Listeria spp \\
\hline Group & - & - \\
\hline 1) A1, B(yes), C(no), D(a) & - & - \\
\hline 2) A1, B(yes), C(no), D(a) & $1 \times 7^{7}$ & $1 \times 2$ \\
\hline 3) A1, B(no), C(yes), D(a) & $2 \times 6$ & $1 \times 5$ \\
\hline 4) A1, B(yes), C(yes), D(a) & $1 \times 11+6 \times 14$ & $2 \times 4$ \\
\hline 5) A1, B(yes), C(yes), D(b) & - & - \\
\hline 6) A2, B(yes), C(no), D(a) & - & - \\
\hline 7) A2, B(yes), C(no), D(a) & $1 \times 8$ & $1 \times 5+1 \times 3$ \\
\hline 8) A2, B(no), C(yes), D(a) & $2 \times 8$ & $1 \times 2$ \\
\hline 9) A2, B(yes), C(yes), D(a) & $1 \times 8+3 \times 14$ & $1 \times 5$ \\
\hline 10) A2, B(yes), C(yes), D(b) & - & - \\
\hline 11) A3, B(no), C(no), D(a) & - & - \\
\hline 12) A3, B(yes), C(no), D(a) & $1 \times 9$ & - \\
\hline 13) A3, B(no), C(yes), D(a) & - & - \\
\hline 14) A3, B(yes), C(yes), D(a) & $6 \times 14$ & $3 \times 5$ \\
\hline 15) A3, B(yes), C(yes), D(b) & 24 & 11 \\
\hline Total & & \\
\hline
\end{tabular}


A: size of the flock (1) up to 10 birds, (2) 10-20 birds (3) more than 20 birds

B: presence of other poultry species in the household

$\mathrm{C}$ : presence of small ruminants in the household

D: feeding practice (a) leftovers of vegetable origin, (b) concentrated feeds

${ }^{a}: 1 \times 7$ : 1strain showing resistance against 7 antibiotics 